\title{
Research on Aerodynamic Characteristic for EMU Passing by Windbreak Wall Gap under Crosswind
}

\section{Dongping Wang ${ }^{1, a}$, Dongdong Chen ${ }^{1}$, Ming Li ${ }^{2, b}$, Gaofeng Liu ${ }^{1}$}

${ }^{1}$ School of Mechanical Engineering, Dalian Jiaotong University, Dalian, 116028, China

${ }^{2}$ TangShan Railway Vehicle Co.,Ltd,Tangshan, 064099, China

awdp1962@163.com, bsjc_liming@tangche.com

Keywords: Numerical simulation, Dynamic grid technology, Windbreak wall gap, Aerodynamic characteristics

\begin{abstract}
When the EMU(Electric Multiple Units) is passing by the windbreak wall gap, the crosswind strikes at its surface, causing the aerodynamic performance exceeds the standards and making influence on the train safety and the passenger comfort. Therefore, the study of this problem is particularly important. Based on the basic control equations of three dimensional, incompressible, unsteady, viscous flow, standard $k-\varepsilon$ equation as well as dynamic grid technology, this paper studies the aerodynamic characteristics of the EMU passing by the windbreak wall gap with the speed of $200 \mathrm{~km} / \mathrm{h}$ under $25 \mathrm{~m} / \mathrm{s}$ crosswind, obtains the change law of the cross force coefficient and the overturning moment coefficient of the train. The results shows that the values are almost stable before the train passing by the windbreak wall gap. But when the train is passing by the gap, the values reach the maximum and then reduce rapidly to the minimum. After passing by the gap, the values return to steady again. Among them, the cross force coefficient and the overturning moment coefficient of the head car are the maximum, and the values are 0.1488 and 0.0718 respectively. So the safety of the head car is the worst.
\end{abstract}

\section{Introduction}

The environment in western China, especially Lanzhou-Xinjiang high-speed railway, is extremely terrible. Strong wind and sand do great harm to the high speed train. So building windbreak wall to defense along the railway is necessary [1,2]. In order to facilitate the workers to clean the gravel, clutters and to maintain the railway equipment, the gap must be set in the middle of the windbreak wall. When the EMU(Electric Multiple Units) is passing by the windbreak wall gap, the crosswind impacts on the surface of train and generate huge pressure, and the value reaches the peak in a very short time. The pressure impacts on the surface of the trains, making a great influence on the security, and it results in the aerodynamic characteristics over standards during the train is passing by those places. So the researches of aerodynamic characteristics on this problem have practical meaning.

In recent years, the researches on the aerodynamics of EMU have received quickly development, especially the aerodynamic characteristics under the crosswind. The literature [3] recommends aerodynamic parameter's change with the moving of the windbreak's height and location, and points out that the windbreak wall has the best height. The literature [4] studies the influence of the drafty windbreak's structural parameters on the wind load along the Nan-Jiang railway viaduct. The literature [5] does the numerical simulation on the aerodynamic force of the EMU and hole-type windbreak wall under the condition of the strong crosswind and high-fill embankment . Those literature about the aerodynamic characteristic only research on the windbreak of different shapes. 
Up to now, any literature about the aerodynamic characteristic during the trains passing by the windbreak wall gap haven't been published. So it has a very important sense to study the project.

Based on this analysis, this paper builds the three-dimensional flow-field computational model of five cars, and does numerical study on the aerodynamic characteristics of the trains with the speed of $200 \mathrm{~km} / \mathrm{h}$ passing by the windbreak wall gap under $25 \mathrm{~m} / \mathrm{s}$ strong crosswind, provided reliable bases for enterprises to research and develop.

\section{The Flow Filed Algorithm}

When the EMU is passing by the windbreak wall gap, the structure of flow field around the train has been changed, belonging to the three-dimensional unsteady, viscous, incompressible turbulent flows. The governing equations of the air flow include the continuity equation, the Reynolds-averaged Navier-Stokes equations (RANS), and the turbulence model equations. In this paper, the standard $k-\varepsilon$ turbulence equation is chosen, and the near wall surface is treated by the wall function method. The SIMPLE algorithm are applied to solve discrete equations, the convection term is based on the second-order upwind scheme, and the viscous term is based on the second-order central differential scheme.

\section{Model and the Grid}

Model. Build the computational model of five cars. The pantograph and bogie are also simplified, as shown in Fig. 1.

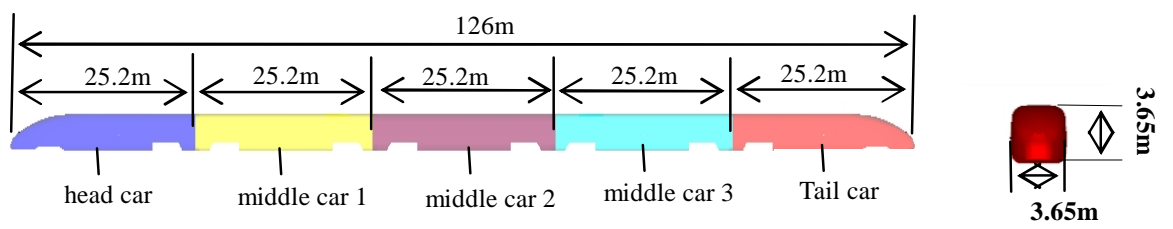

Fig. 1 The computational model of five cars

The boundary of external flow field should be far away from the train in order to reduce its influence. The literature [6] shows that, the outside flow field's length is at least three times of the train's, and its width is at least ten times of the train's. All of those determined the entire computational domain size which is $826 \mathrm{~m} \times 300 \mathrm{~m} \times 100 \mathrm{~m}$, as shown in Fig. 2. At the initial time, the tail of EMU is $100 \mathrm{~m}$ away from the entrance. After having ran $248 \mathrm{~m}$, it starts passing by the windbreak wall gap. When the train is $100 \mathrm{~m}$ far from the exit, the calculation is over. The height of the windbreak wall is $3 \mathrm{~m}$, the width is $1.5 \mathrm{~m}$ [7], and the length of the gap is $4 \mathrm{~m}$ [8], as shown in Fig. 3

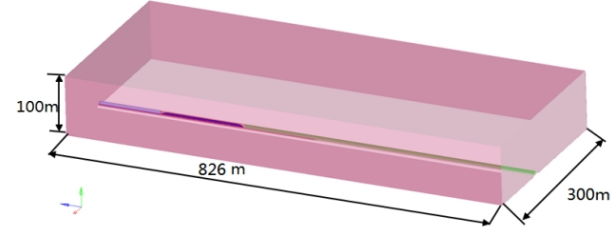

(a) Flow field domain

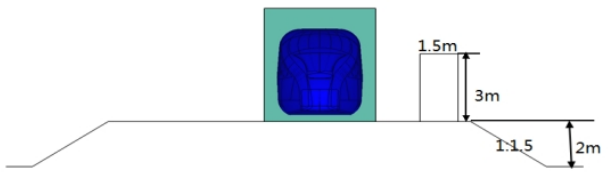

(b) The structure of windbreak wall

Fig. 2 The whole calculated flow field and the windbreak wall structure 


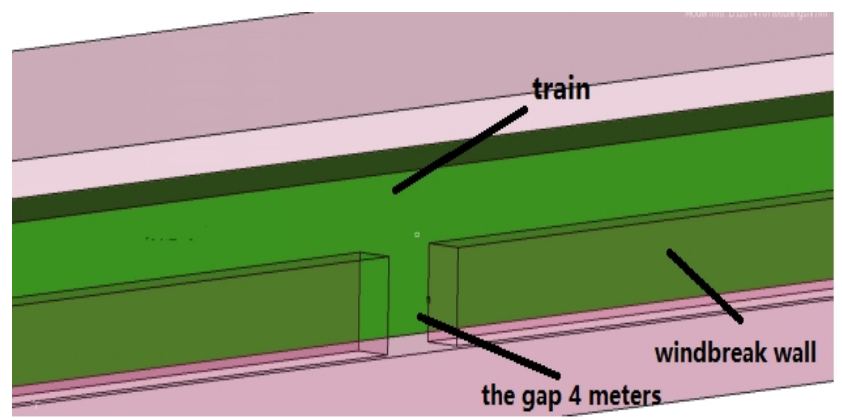

Fig. 3 The location of the gap

In order to study the change law of pressure on the body surface, the pressure monitoring points on the center of car-body are set.

Points $\mathrm{n} 1$ to $\mathrm{n} 5$ are equally distributed in the middle of the train which belong to the side of the windbreak wall, and points w1 to w5 are equally distributed in the middle of the train on the opposite side, as shown in Fig. 4.

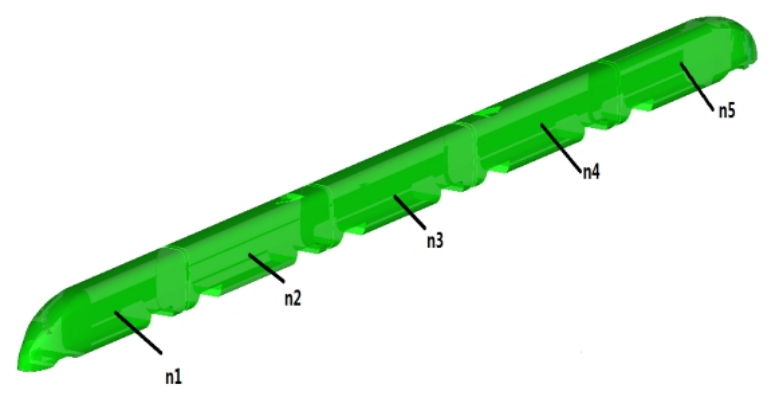

(a) On the side of windbreak wall

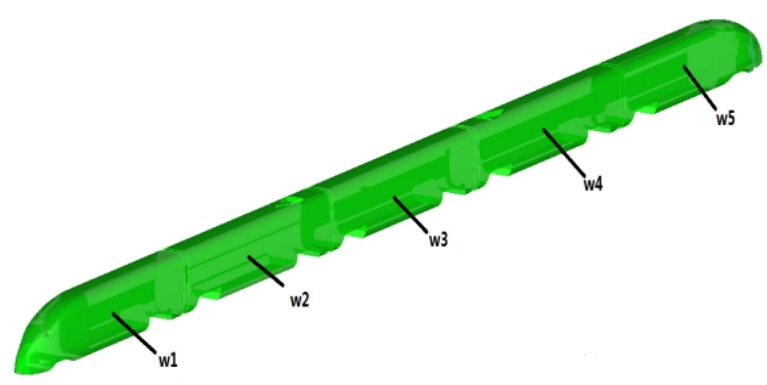

(b) On the side without windbreak wall

Fig. 4 Monitoring point distribution

Meshing. In the definition of the dynamic grids, the moving boundary is defined by type-function, and the updating way of the dynamic mesh is layering method. The surrounding flow field of the train is static grids, meshed with tetrahedral.The front and rear of the flow field are dynamic grids, using hexahedral grid to mesh. The other parts are external flow field, belonging to static grids too. So the whole flow field can be divided into four parts. Meshing each part respectively, then the interfaces between the four parts are defined by INTERFACE for data changing. The number of grids is 11.23 million, the quality is well.

\section{Pressure and Velocity Vector Diagrams}

The operating conditions are as follows: under $25 \mathrm{~m} / \mathrm{s}$ crosswind, the train passes the windbreak wall gap with the speed of $200 \mathrm{~km} / \mathrm{h}$.

This paper first studies the no crosswind condition. The research shows that the pressure on the train which running with the speed $200 \mathrm{~km} / \mathrm{h}$ is relatively stable when passing by the windbreak wall gap. The nose tip pressures of the train changes between 1790-1820Pa. Comparing with the theoretical value, the nose tip pressure maximum relative error reaches $5.29 \%$, but less than $10 \%$, which shows that the calculated results are reliable. The next step is to simulate the $25 \mathrm{~m} / \mathrm{s}$ crosswind conditions.

The middle car 1 is just located in the windbreak wall gap at the time of 5s. Fig. 5 is the 
horizontal pressure contour at $5 \mathrm{~s}$ ( $4 \mathrm{~m}$ from the ground). Fig. 6 is the local horizontal section velocity vector diagram at $5 \mathrm{~s}$ ( $4 \mathrm{~m}$ from the ground).

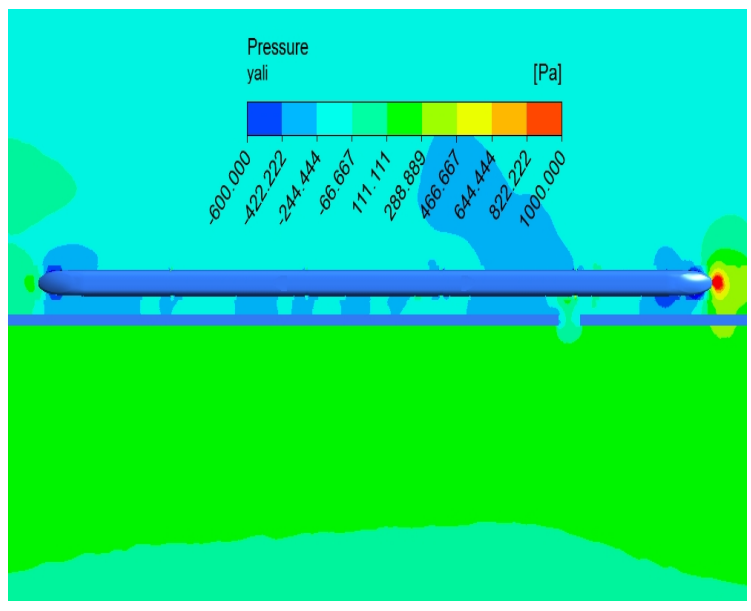

Fig. 5 Horizontal pressure contour (4m from the ground)

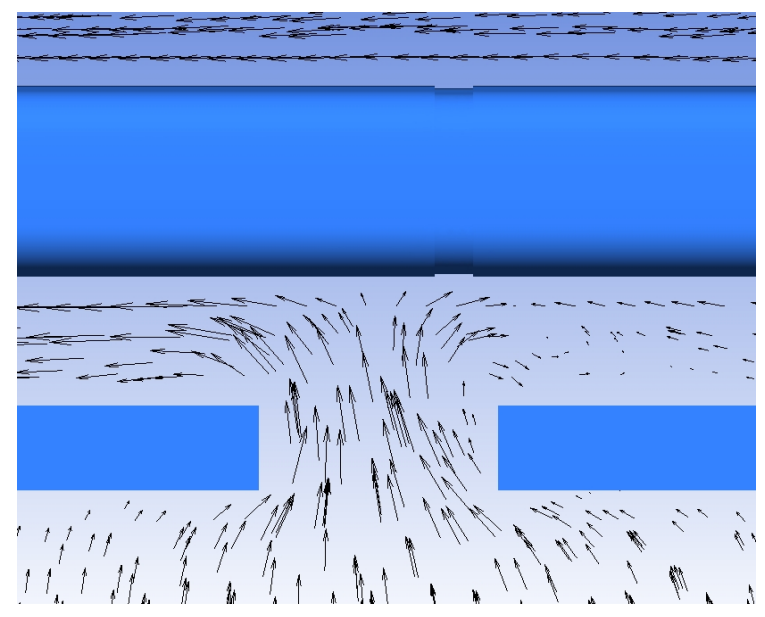

Fig. 6 The local horizontal section velocity vector diagram

It can be seen from the pictures above, when the body passes by the windbreak wall gap, the airflow can strike directly to the body surface, generating higher pressure and then forming sudden huge pressure difference on the both side of the body. As a result, the cross force increases suddenly, resulting in that train has the overturning tendency toward the side without windbreak wall.

\section{Contrast and Analysis of the Monitoring Points' Pressures of the EMU}

The whole process of the train passing by the windbreak wall gap is described as follows: at the initial time, the tail of the EMU was $100 \mathrm{~m}$ away from the entrance. Then the train began to pass by the windbreak wall gap at $4.45 \mathrm{~s}$. At the time of $6.796 \mathrm{~s}$, the train left the windbreak wall gap. The whole process lasted 2.346s. It was finished until the head of EMU was $100 \mathrm{~m}$ away from the exit at the time of $9 \mathrm{~s}$. 
Fig. 7 shows the monitoring points' pressures histories in the five cars.

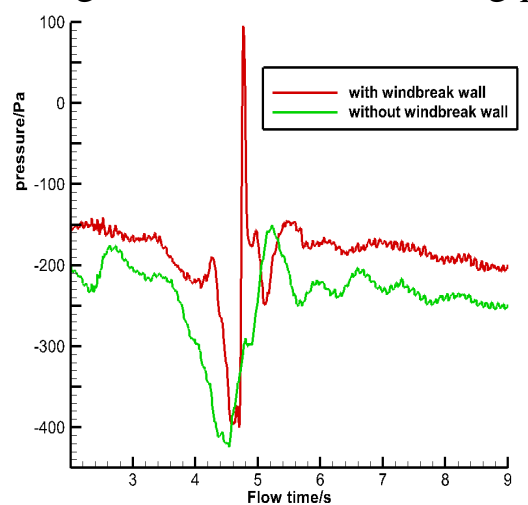

(a) Head car

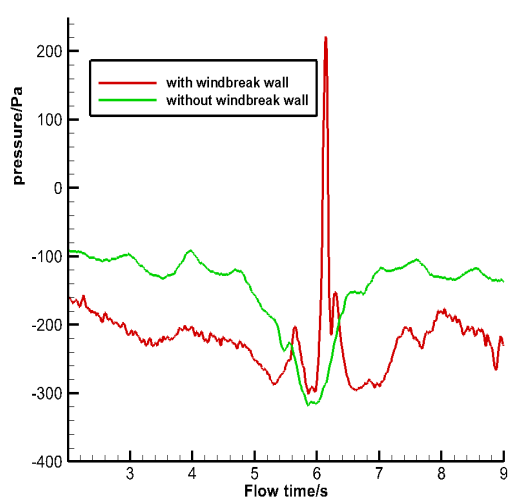

(d) Middle car 3

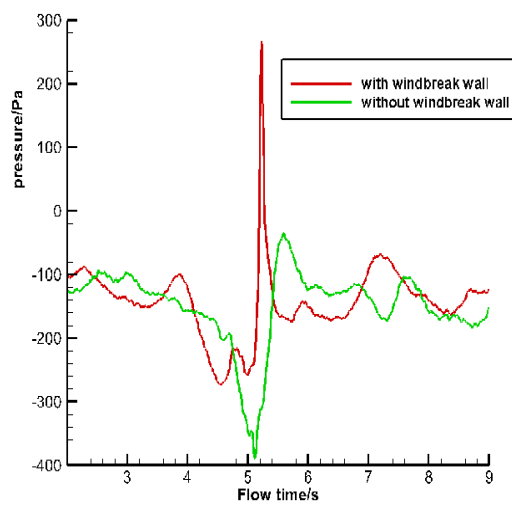

(b) Middle car 1

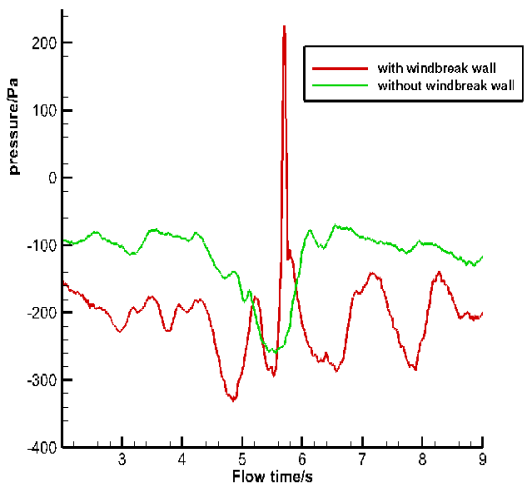

(c) Middle car 2

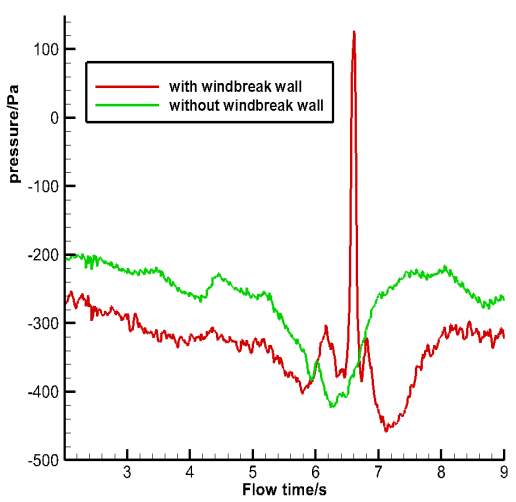

(e) Tail car

Fig. 7 Pressure histories at corresponding central monitoring points on both sides of the train

Fig. 7 shows that pressure histories of measuring points on different cars have the same trend. As the cars passing by the windbreak wall gap at different times, pressure peaks on measuring points appear a little delay with the cars farther from the head car. Fig. 7(a) is the pressure contrasting between $\mathrm{w} 1$ and $\mathrm{n} 1$ of the head car. Before the head car passes by the gap, the maximum pressure difference on both sides is about $170.97 \mathrm{~Pa}$. In the process of the head car passing by the gap, the pressure on the windbreak wall side reaches maximum, and the value is $95.2 \mathrm{~Pa}$ at $4.77 \mathrm{~s}$. The pressure on the other side is $-304.97 \mathrm{~Pa}$. Pressure difference is $400.17 \mathrm{~Pa}$, increasing by $134 \%$ than before.

\section{Analysis of Cross Force Coefficient and Overturning Moment Coefficient}

Define cross force coefficient as $C_{x}$, overturning moment coefficient as $C_{m_{x}}$

$$
\begin{aligned}
& C_{x}=\frac{F_{x}}{\frac{1}{2} \rho V^{2} A_{x}} \\
& C_{m_{x}}=\frac{M_{x}}{\frac{1}{2} \rho V^{2} A_{x} H_{g}}
\end{aligned}
$$

$C_{x}:$ cross force coefficient; $F_{x}:$ cross force; $\rho:$ air density; $A_{x}:$ reference area, here represents 
train's cross section $\left(\mathrm{m}^{2}\right) ; C_{m_{x}}$ : overturning moment coefficient; $M_{x}$ : overturning moment; $H_{g}$ : reference height, here represents train's height (m).

In Fig. 8, cross force coefficient and overturning moment coefficient histories are shown in different cars. It is seen that the curves are relatively stable before different cars arrived in windbreak wall gap. When they are passing by the gap, the two coefficients reach the maximum value, then begin to down to the minimum, and finally return to stable states.

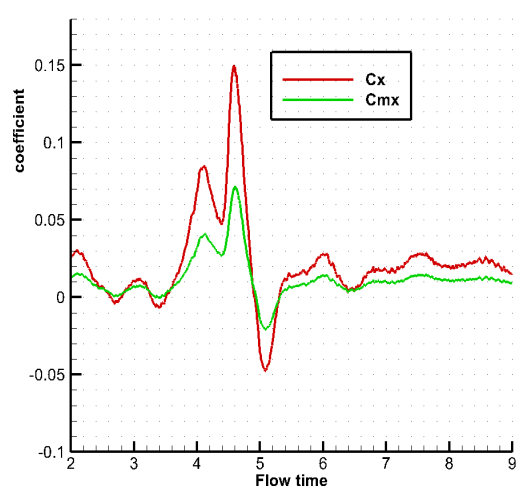

(a) Head car

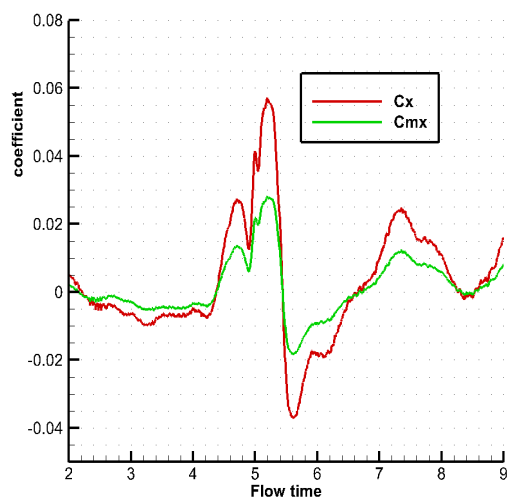

(b) Middle car 1

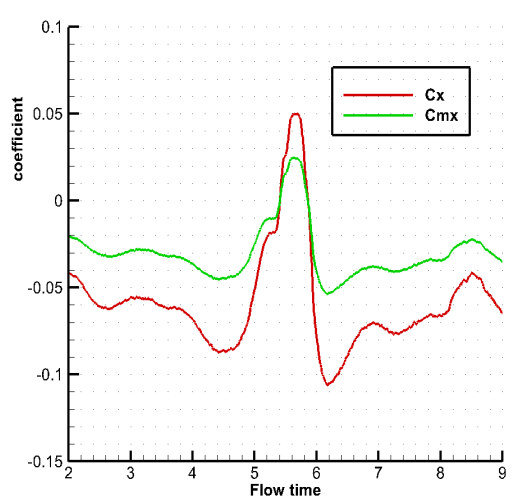

(c) Middle car 2

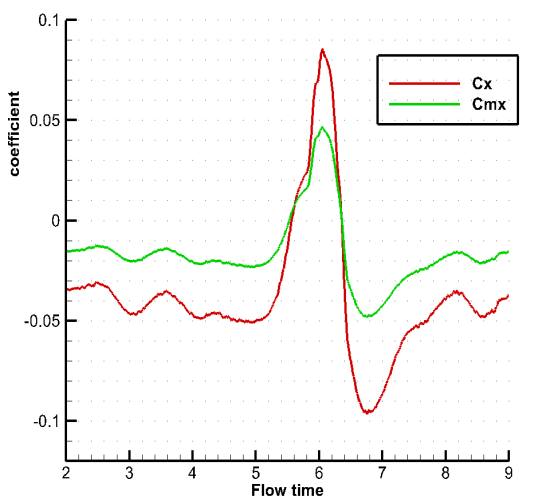

(d) Middle car 3

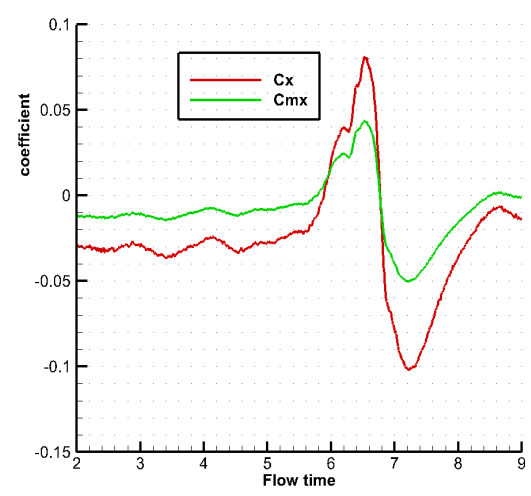

(e) Tail car

Fig. 8 Cross force coefficient and overturning moment coefficient histories in different cars

In Fig. 8(a), the change law of the cross force coefficient and the overturning moment coefficient are shown for head car when the train passes by the windbreak wall. The head car begins to arrive at the gap at $4.456 \mathrm{~s}$, and at the time of $4.982 \mathrm{~s}$ the tail of the head car has just left the gap. When the head car has not arrived at the gap, the maximum value of cross force coefficient is 0.0848 , and the maximum overturning moment coefficient is 0.0409. During the time that the head car arrives at the gap, the two coefficients increase. The cross force coefficient reaches maximum 0.1488 at $4.595 \mathrm{~s}$, increasing by $75.5 \%$. The overturning moment coefficient reaches maximum 0.0718 at $4.605 \mathrm{~s}$, increasing by $75.6 \%$. After the head car has just left the gap, the cross force coefficient reduces to a minimum -0.0477 at $5.08 \mathrm{~s}$, and the overturning moment coefficient reduces to a minimum -0.0207 at $5.09 \mathrm{~s}$. But soon the two coefficients rise gradually until they remain stable. The specific values of each body are shown in Table 1 and Table 2 .

In conclusions, the train runs with the speed of $200 \mathrm{~km} / \mathrm{h}$ under $25 \mathrm{~m} / \mathrm{s}$ crosswind. The maximum cross force coefficient of middle car 2 is 0.0502 , the maximum overturning moment coefficient is 0.0249. Compared with the values of middle car 2 , the maximum cross force coefficient of other bodies are higher respectively 196\%, 13.7\%, 70.9\%, 61.4\%, and the maximum overturning moment 
coefficient are higher respectively $189 \%, 13 \%, 87.1 \%, 75.5 \%$. So the head car's maximum cross force coefficient and maximum overturning moment coefficient are $0.1488,0.0718$ respectively. As a result, the safety of the head car is the worst.

Table 1 Contrast of cross force coefficient

\begin{tabular}{cccccc}
\hline body & $\begin{array}{c}\text { the maximum value } \\
\text { before the gap }\end{array}$ & $\begin{array}{c}\text { The maximum value } \\
\text { in the gap }\end{array}$ & $\begin{array}{c}\text { the minimum value } \\
\text { after the gap }\end{array}$ & $\begin{array}{c}\text { growing } \\
\text { rate }(\%)\end{array}$ & $\begin{array}{c}\text { relative increasing } \\
\text { rate }(\%)\end{array}$ \\
\hline Head car & 0.0848 & 0.1488 & -0.0477 & 75.5 & 196 \\
\hline Middle car 1 & 0.0275 & 0.0571 & -0.0372 & 108 & 13.7 \\
\hline Middle car 2 & -0.0415 & 0.0502 & -0.1062 & 221 & 0 \\
\hline Middle car 3 & -0.0308 & 0.0858 & -0.0961 & 378 & 61.4 \\
\hline Tail car & -0.0237 & 0.081 & -0.1022 & 442 & 6.9 \\
\hline
\end{tabular}

Note: Growing rate $(\%)=($ the maximum value in the gap - the maximum value before the gap) $/ \square$ the maximum value before the gap $\square \times 100(\%)$

Relative increasing rate $(\%)=($ the maximum value in the gap of $\mathrm{N}$ car - the maximum value in the gap of Middle car 2 ) / the maximum value in the gap of Middle car $2 \times 100(\%)$

Table 2 Contrast of overturning moment coefficient

\begin{tabular}{cccccc}
\hline body & $\begin{array}{c}\text { the maximum value } \\
\text { before the gap }\end{array}$ & $\begin{array}{c}\text { The maximum value } \\
\text { in the gap }\end{array}$ & $\begin{array}{c}\text { the minimum value } \\
\text { after the gap }\end{array}$ & $\begin{array}{c}\text { growing } \\
\text { rate }(\%)\end{array}$ & $\begin{array}{c}\text { relative increasing } \\
\text { rate }(\%)\end{array}$ \\
\hline Head car & 0.0409 & 0.0718 & -0.0207 & 75.6 & 188 \\
\hline Middle car 1 & 0.0137 & 0.0281 & -0.0812 & 105 & 13 \\
\hline Middle car 2 & -0.0206 & 0.0249 & -0.0538 & 221 & 87.1 \\
\hline Middle car 3 & -0.0126 & 0.0466 & -0.0483 & 470 & 707 \\
\hline Tail car & -0.0072 & 0.0437 & -0.0504 & & 75.5 \\
\hline
\end{tabular}

Note: as well as the note of the Table 1

\section{Conclusions}

In this paper, the aerodynamic characteristics of the EMU passing by the windbreak wall gap can be analyzed, making some conclusions as follows:

(1) When the train is passing by the windbreak gap with the speed of $200 \mathrm{~km} / \mathrm{h}$, comparing with the theoretical value, the nose tip pressure maximum relative error reaches $5.29 \%$, but less than $10 \%$, which shows that the calculated results are reliable.

(2) Under $25 \mathrm{~m} / \mathrm{s}$ crosswind, the train passes by the windbreak gap with speed of $200 \mathrm{~km} / \mathrm{h}$, the change law of the cross force coefficient and the overturning moment coefficient are almost the same. When each body of the train runs before the windbreak wall gap, the cross force coefficient and the overturning moment coefficient are almost stable, but when they are just passing by the gap, these values reach the maximum and then reduce rapidly to the minimum. After passing by the gap, they return to steady.

(3) When the train is passing by the windbreak wall gap, the head car's maximum cross force coefficient and maximum overturning moment coefficient are $0.1488,0.0718$ respectively. As a result, the safety of the head car is the worst. 


\section{Acknowledgement}

This work was financially supported by TangShan Railway Vehicle Co.,Ltd.

\section{References}

[1] Jiaqiang Liu: Journal of Science and Technology of West, Vol. 7 (2008) No.4, p. 43

[2] Fenghua Liu: Journal of Central South University (Science and Technology), Vol. 37 (2006) No.1, p. 176

[3] Cuixiang Jiang, Xifeng Liang: Journal of China Railway Science, Vol. 27 (2006) No.2, p. 66

[4] Jiping Zheng: Study on the Behaviors of Bridge Windbreak of Nan-Jiang Railway( Southwest JiaoTong University, China 2008). (In Chinese)

[5] Yanfei Li, Hongqi Tian, Hui Liu: Journal of Central South University (Science and Technology), Vol. 42 (2011) No.10, p. 3208

[6] Dongping Wang, Qiaoqi Xu, Shaoze Zhou: Journal of Dalian JiaoTong University, Vol.31(2010) No.3, p. 17

[7] Xuekai Wang: Journal of Subgrade Engineering, 2012, No.5, p. 181

[8] Gang Xu : Research and Optimization of Windbreak Wall Transition Section Flow Characters on Lanzhou-Xinjiang Railway( Central South University, China 2010). (In Chinese) 